\title{
Comparison of Vase Life on Treatments with Combinations of Postharvest Solutions of Cut Hydrangea Flowers (Hydrangea macrophylla cv. 'Verena') in Distribution Stage
}

\author{
Haejo Yang ${ }^{1}$, Sooyeon Lim ${ }^{1}$, Ji Hyun Lee ${ }^{1}$, Ji Weon Choi ${ }^{1}$ and Il Sheob Shin ${ }^{1 *}$ \\ ${ }^{1}$ Postharvest Technology Division, National Institute of Horticultural and Herbal Science, RDA, Wanju \\ 55365, Korea \\ * Correspondence author: $\underline{\text { shinis3@korea.kr }}$
}

\begin{abstract}
Vase life is one of the most important factors that determine the marketability of cut flowers and is greatly affected by the water balance. In recent years, cut hydrangea flowers are increasingly consumed as decorations for various events. However, the vase life of cut hydrangea flowers varies greatly depending on the postharvest solution management. Therefore, this study investigated the vase life, solution uptake, water balance, and relative fresh weight of freshly harvested hydrangea (Hydrangea macrophylla 'Verena') according to the three types of holding solutions (tap water, $1 \%$ chrysal professional III (CPIII), 2\% sucrose + $250 \mathrm{mg} / \mathrm{L} 8$ hydroxquinoline $+100 \mathrm{mg} / \mathrm{L}$ citric acid (SHQC)) and the combination solutions (pretreatment; tap water, $0.1 \%$ chrysal RVB (RVB), floralife quickdip (FQ), transport; tap water, $\mathrm{CPIII}$, floralife clear (FC), preservatives; $\mathrm{CP} I I, \mathrm{FC}$ ) for each distribution stage (pretreatment-transport-consumer). In the preservative comparison experiment, compared with the control, CPII treatment and SHQC treatment significantly increased the vase life in 2019 (0.7 days, 3.4 days) and 2020 (1.4 days, 3.1 days), respectively. In the comparative experiment by solution combination, the group (RVB, FQ) using the pretreatment significantly extended the vase life by 4.6 days and 5.9 days compared to the tap water treatment. It was also determined that the same treatment increased overall solution uptake, maintained water balance longer, and increased relative fresh weight. These results confirm the importance of holding
\end{abstract}


solutions and pretreatments, suggesting that appropriate pretreatments and preservatives should be used to improve the marketability of cut hydrangea flowers.

Additional key words: cut flower, holding solution, pretreatment, transport, sucrose

\section{Introduction}

Hydrangea (Hydrangea spp.) is an ornamental plant for widely using in the garden and potted plant, and also for cut flower production. Especially, Hydrangea macrophylla is the most cultivated cultivar among the Hydrangea species. Hydrangea inflorescences are classified into two types: hortensia, lace caps, depending on the arrangement of decorative and nondecorative flowers. Hortensia-type hydrangea, which has a high market share in the cut flower market, is classified into two stages: fresh stage and antique stage depending on the harvest stage [1].

Vase life of cut hydrangea flowers harvested in fresh stage is usually short, between 7 and 15 days [2]. Vase life is one of the most important quality factors affecting the marketability and customer's satisfaction of cut hydrangea flowers [3]. An important factor in determining the quality of cut flowers is known as vase life, which is affected by water absorption and evaporation [4]. Water absorption and evaporation of cut hydrangea flowers in all cut flowers is associated with catabolism such as respiration and decreases due to vascular occlusions by air embolism and microorganisms. In particular, microorganisms block the ends of cut flowers stem, inhibiting solution uptake and shorten the vase life $[1,5]$. To solve this problem, some studies have been conducted to extend the vase life of cut flowers by adding various disinfectants to vase water [6-10]. Also, the most important problem after harvesting of cut flower hydrangea is that if the water supply is not maintained, which causes 
air embolism. Air embolism in xylem conduits can partially or completely block the water transport path between roots and sinks for water in plants [11]. The wilting is sometimes caused by air embolism, and the wilting is a criteria for the end of the vase life, and, vase life of cut hydrangeas is shortened due to sepal browning and wilting [12]. To prevent wilting by air embolism, cut flowers should be pretreatment immediately after harvesting, moisture management during transport, and preservative solution treatment at the consumer stage.

In many previous studies, aluminum sulfate, 8-hydroxyquinolin, 8-hydroxyquinolin sulfate (8-HQS), 8-hydroxyquinolin citrate, ethanol, and sodium hypochlorite are typically used as disinfectants. In particular, 8-HQS is one of the very important disinfectant use in cut flowers and has been reported to have an positive effect on microbial growth inhibition [1315]. However, despite these advantages, the effects depend on the cultivar and dose, and toxicity occurred in some cultivars due to high doses or long storage times [16]. Therefore, it is very important to find the optimal solution combination that will be readily available on the cultivation site and at the consumer stage. Although many studies have been reported about the cut hydrangea vase life such as the effect of 8-HQS, relationship between decorative sepal surface and transpiration, and different harvest stage, few studies have compared the practical use of farmhouses $[4,17,18]$.

The market for hydrangea is largely divided into domestic and export, and is commonly subdivided into harvest-transport-sale. In order to maintain the quality of cut flowers, proper vase solution treatment (pretreatment after harvesting, water container during transportation, preservative solution after purchase) should be performed at each distribution stage.

In this study aimed to determine the effect of treatments such as pretreatment, transport solution, and preservative solution at the level currently used in the cultivation field on the 
vase life of cut hydrangea flowers.

\section{Materials and methods}

\section{Plant Materials}

The hydrangea cultivars used in this experiment were those that are widely sold in Korea, and all were harvested in fresh stages. The cut hydrangea flower samples were 'Verena'

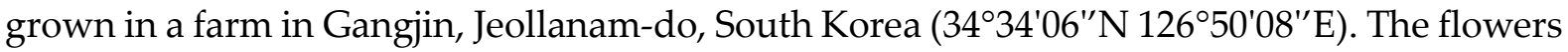
were harvested at the commercial stage, which about $80 \%$ of the florets had showed the colours of the cultivar in June of 2019, 2020. The harvested flowers were immediately pretreated in a cold storage at $4{ }^{\circ} \mathrm{C}$. After pretreatment, they were re-cut to a length $60 \mathrm{~cm}$ and put in a water container and transported to the postharvest laboratory within three hours. Then, the flowers were stored 72 hours at $4{ }^{\circ} \mathrm{C}$ to transport conditions during simulated export. After simulated transport, the flower stems were re-cut to a length of $48 \mathrm{~cm}$ and five upper leaf was held on each stem for vase life evaluation .

\section{Treatment Solutions}

For comparison by Holding solution treatment, holding solution were used $1 \%$ chrysal professional III (CPIII), 2\% sucrose $+250 \mathrm{mg} / \mathrm{L}$ 8-hydroxquinoline $+100 \mathrm{mg} / \mathrm{L}$ citric acid (SHQC), and tap water (TW) as control. For comparison by treatments with combinations of postharvest solutions, the pretreatment was immersed in the pretreatment solution immediately after harvest and stored at $4{ }^{\circ} \mathrm{C}$ for 24 hours.

The postharvest solution were used $0.1 \%$ chrysal RVB (RVB), floralife quickdip (FQ), and TW as control. For the transport solution treatment, flowers were put in a water container containing transport solution and then packed in a cardboard box and stored at $4{ }^{\circ} \mathrm{C}$ for 72 
hours, which was simulated transported with consideration for the transport period from packaging to sales. The transport solution were used CPIII, floralife clear (FC), and TW as control. The holding solution treatment was put in glass bottle $(1000 \mathrm{ml})$ containing $700 \mathrm{ml}$ of holding solution which were CPIII and FC. All solutions were prepared freshly at the initiation of the study. The condition of vase life evaluation room were that fluorescent lamp was turned on for 12 hours from 6 am to 6 pm every day and room temperature was $22 \pm 1{ }^{\circ} \mathrm{C}$, relative humidity was $60 \pm 5 \%$.

\section{Relative Fresh Weight, Solution Uptake, Water Balance, and Vase life}

Fresh weight and solution uptake were determined once every 2 days and the weight of the vase with and without flower. Fresh weight was calculated by subtracting the weight of vase and solution from total weight of vase, solution, and flower. Relative fresh weight was calculated as the rate of fresh weight change, which was calculated as a percentage of fresh weight at the day of measurement compared to fresh weight at the day of initial. Solution uptake was investigated by subtracting the weight of vase and solution on the day of measurement from the weight of vase and solution on the previous day. Total solution uptake was calculated by adding up all daily solution uptake. Water balance was investigated by subtracting transpiration from solution uptake, and transpiration was investigated by subtracting the total weight on the day of measurement from the total weight on the previous day. Vase life was defined by the duration from the initial of experiment to the occurrence of wilting, browning, and dry. The degree of flower wilting, browning, dry and vase life of flowers was determined according to the morphological stages and appearance of symptoms such as drying, brown edges, wilting flower, bent neck (Fig. 1). 


\author{
Relative fresh weight $(\%$ of initial $)=\left(\mathrm{W}_{\mathrm{t}} / \mathrm{W}_{0}\right) * 100$ \\ $\mathrm{W}_{\mathrm{t}}=$ the weight of flower stem $(\mathrm{g})$ at the day of measurement \\ $\mathrm{W}_{0}=$ the weight of flower stem $(\mathrm{g})$ at the day of initial
}

\title{
Statistical Analysis
}

The experiment with five treatments was conducted in completely randomized design (CRD) with nine replicates and one flowers for each replication. For statistical analysis, analysis of variance (ANOVA) was performed using SPSS 20 program (SPSS Inc., Chicago, IL, USA), and Duncan's multiple range test was used for the significance of each average value $(\mathrm{p}<0.05)$

\section{Results}

\section{Relative Fresh Weight due to Holding Solution}

Fresh weight results were expressed as relative fresh weight, and the results of relative fresh weight for each holding solution treatments are shown in fig. 2. Relative fresh weight of SHQC treatment increased sharply until the 8 days and 11 days, respectively (Fig. 2). As a result in 2019, TW and CPIII treatment decreased by 1.65 and $0.30 \%$, respectively, compared to initial weights, whereas the SHQC treatment increased by $0.32 \%$ at 12 days (Fig. 2a). As a result in 2020, fresh weight of all treatments increased compared to initial weights at 14 days. In particular, SHQC treatment increased by $4.5 \%$, which was significantly increased compared to other treatments. However, relative fresh weight of SHQC treatment rapidly decreased at the end of vase life (Fig. 2b). 


\section{Relative Fresh Weight due to Combination of Postharvest Solution}

The results of relative fresh weight by combination of postharvest solution treatment in the distribution stages were shown in Fig. 5a. There was a slight difference in the maintenance period of fresh weight for each treatment. RVB-CPIII-CPIII combination had the longest fresh weight maintenance period of 25 days than other treatments, and showed a difference of about 4 to 7 days. During vase life, RVB-CPIII-CPIII combination was $7.3 \%$, which was significantly higher from $6.3 \%$ to $9.4 \%$ than those without pretreatment. It was similar to the FQ-FC-FC combination, there was no significant difference.

\section{Solution Uptake and Total Solution Uptake due to Holding Solution}

Solution uptake decreased until the 10th day after holding solution treatment in all treatments, and tap water treatment was the least until 6 days after treatment, but there was no significant difference between treatments. In addition, $\mathrm{CPIII}$ treatment and SHQC treatment maintained solution uptake as much as the initial solution uptake level until the end of vase life (Fig. 3a). Total solution uptake in 2019 was $199.08 \mathrm{~g} / \mathrm{stem}$ in CPIII treatment, which was higher than tap water treatment $(138.00 \mathrm{~g} / \mathrm{stem})$ and SHQC treatment $(163.54$ g/stem) (Table 3). As a result of 2020, the initial solution uptake of the three treatments was $15.3,15.9$, and $16.3 \mathrm{~g} / \mathrm{stem}$, respectively, and the difference in absorption between TW and CP III, SHQC treatments was $0.6 \sim 1 \mathrm{~g} / \mathrm{stem}$, which was similar. Changes in solution uptake during preservation period of cut flowers were $8.9,11.4$, and $12.0 \mathrm{~g} /$ stem at 21 days, respectively. The difference in solution uptake between TW and treatment with CPIII and SHQC ranged from $2.5 \mathrm{~g} / \mathrm{stem}$ to $3.1 \mathrm{~g} / \mathrm{stem}$, and there was a statistically significant difference between the control and treatment groups (Fig. 3b). In 2020, the total solution uptake of CPIII and SHQC was 
135.28 and $132.71 \mathrm{~g} / \mathrm{stem}$, respectively, which was statistically significantly higher than tap water (Table 3).

\section{Solution Uptake and Total Solution Uptake due to Combination of Postharvest Solution}

The results of solution uptake and total solution uptake by combination of postharvest solution treatment in the distribution stages were shown in Table 4 and Fig. 5b. Solution uptake gradually decreased during preservation period of cut flowers in common for all treatments. In particular, solution uptake of cut flowers treated with the TW-TW-CPIII combination decreased sharply from 18 days. TW- CPIII- CPIII combination, which was dipped with TW without using a pretreatment agent, and then distributed and preserved with CPIII solution, showed a clear decrease from 21 days. On the other hand, the RVB-CPIII-CP III combination and FQ-FC-FC combination maintained solution uptake during vase life compared to other combinations. This finding was statistically significant both by using Duncan's multiple test between absolute values and with repeated measurements. The total solution uptake by each postharvest solution was $164.92 \mathrm{~g} /$ stem in RVB-CPIII-CPIII combination, which was the highest compared to other treatments, but there was no statistically significant difference between treatments.

\section{Water Balance due to Holding Solution}

The water balance results according to the holding solution treatment showed a similar trend to the 2019 and 2020 results, and water balance of SHQC treatment was maintained longer than that of other treatments. The number of days to maintain the water balance is the date at which water balance value changes from a positive value to a negative value. As a 
result of 2019, the number of days to maintain water balance of SHQC treatment was 8 days, which was maintained for 2-4 days longer than 6 days for CPIII treatment and 4 days for TW (Fig. 4a). In the study conducted in 2020, the number of days for maintain water balance in SHQC treatment was 11 days, which was 2-7 days longer than 9 days for $\mathrm{CPIII}$ treatment and 4 days for TW (Fig. 4b).

\section{Water Balance due to Combination of Postharvest Solution}

The results of water balance according to the solution management in the overall process from pre-harvest treatment to preservation solution showed a dramatic effect depending on the treatment (Fig 5c). The effect of maintaining the water balance according to the treatment of the transport solution used in the distribution stage was insignificant. The number of days for maintaining water balance between the TW-TW-CPIII combination and the TW- CPIII-CP III combination was the same as 9 days, so there was no difference between TW and CPIII used as a transport solution. However, due to the use of pretreatment, the number of days for maintaining water balance was slightly extended. The number of days for maintaining water balance of the RVB-CPII-CPIII combination using the pretreatment was 11 days, which was extended by 2 more days than the TW-CPIII-CPIII combination without the pretreatment. Also, there was a difference in the time when the moisture balance value rapidly decreased depending on whether or not the pretreatment was used. The combination with pretreatments such as RVB and FQ started to decrease from day 21 to day 25, while the combination without pretreatment decreased sharply from day 18.

\section{Vase life}


The use of a preservative was effective in extending the vase life following the treatment with a preservative solution (Table 1). As a result of 2019, vase life of CPIII treatment and SHQC treatment was extended by 0.7-3.4 days compared to TW treatment. The minimum vase life of CPIII treatment was 18 days and the maximum vase life was 23 days, which exceeded the vase life of TW and SHQC treatment. In the 2020 results, the vase life was extended with the CPIII treatment and SHQC treatment compared to the TW. Commonly in 2019 and 2020, $\mathrm{CPIII}$ treatment and SHQC treatment with a preservation solution at the consumer stage was effective in extending the vase life of cut hydrangea flowers. The effect of the pretreatment was clearly verified in the vase life results according to the combination of post-harvest solution of a total of 4 combinations (Table 2). The average vase life of the group pretreated with RVB and FQ were 29.9 and 28.6 days, respectively, which was longer than that of the group without pretreatment. In particular, the vase life of the RVB-CPII-CPIII combination was 27 days at the maximum and 35 days at the maximum, which exceeded the vase life range of the TW-TW-CPIII combination. Through these results, it was confirmed that the use of an appropriate pretreatment agent is an important factor in order to extend the vase life and improve the quality.

\section{Discussion}

Cut hydrangea flowers are sensitive to water stress, and when water is insufficient, the water balance of the calyx changes to a negative value. The main causes of water stress are interruption of water supply and vascular occlusion at the tip of the stem [18]. Most cut flowers, including cut hydrangea flowers, have a high initial solution uptake rate, but decrease 
over time, mainly due to vascular blockage by microorganisms and air embolism [19]. The impact of kept water relations on extending the vase life is constructed on the conclusion that cut roses are sensitive to water shortage caused by disturbing the postharvest water balance $[9,12,20]$. If these causes persist, they wither and the quality of the cut flowers deteriorates, which is the standard for the end of the vase life [1]. Asrar (2012)[13] reported that solution uptake through the preservation solution improves the water balance and freshness of flowers, and reduces early wilting, thereby improving the vase life of cut flowers. In our study, we observed the vase life of cut hydrangea flowers according to the combination of a preservation solution at the consumer stage and a combination of postharvest solution for each distribution stage after harvest for the purpose of improving the marketability of cut hydrangea flowers. For hydrangeas grown in Korea, it usually takes 2-3 days for export to the destination country. During this period, water management should be focused on the pretreatment stage immediately after harvest and the transportation stage. Pretreatment immediately after harvest is an essential step as it is an operation to artificially supply nutrient moisture to cut flowers whose supply of moisture and nutrients is interrupted [21]. In addition, the use of a preservatives used as a post-treatment concept that helps to prolong the flower viewing period at the consumer stage is also effective in extending the vase life. In particular, the various chemical solutions used in this study, such as RVB, CPIII, SHQC, FQ, and FC, generally have a specific purpose, so proper use is required. According to our results about solution uptake and water balance, RVB used as a pretreatment and SHQC treatment used as a holding solution with sucrose absorbed more water than TW treatment, and thus water balance was also improved. In addition, SHQC treatment with $2 \%$ sucrose increased fresh weight compared to TW treatments. These results at fresh weight are similar to the solution 
uptake ratings positively affected by $8-\mathrm{HQ}$ with $2 \%$ sucrose. As such, the maintenance of the water balance according to the increase in the solution uptake and the decrease in the transpiration prevents the loss of water in cut flowers, and thus may have a positive effect on the fresh weight. It was reported in previous studies that there is a relationship between solution uptake and fresh weight $[5,22]$. Previous study showed that the combined effect of sucrose and antibacterial agents on the fresh weight of cut flowers was much greater than that of single use [23]. Sucrose supply is known to increase vase life, and it has been reported that it may act as an osmotic active molecule constituting a water relationship as well as a nutrient source for tissues [24-26]. For these reasons, sucrose retarded fresh weight loss during the ornamental period of cut hydrangeas.

Funding. This research received no external funding.

Acknowledgement. This study was supported by the "Research Program for Agriculture Science and Technology Development (Project no. PJ014342012020) and 2021 the RDA Fellowship Program of (National Institute of Horticultural and Herbal Science), Rural Development Administration, Republic of Korea.

Author Contributions. Conceptualization, Il Sheob Shin and Haejo Yang; Methodology, Il Sheob Shin and Haejo Yang; Validation, Ji Hyun Lee, Sooyeon Lim and Ji Weon Choi; Investigation, Haejo Yang; Resources, Il Sheob Shin; Data Curation, Ji Hyun Lee, Sooyeon Lim and Ji Weon Choi; Writing - Original Draft Preparation, Haejo Yang; Writing - Review \& Editing, Il Sheob Shin; Visualization, Haejo Yang; Supervision, Il Sheob Shin; Project 
Administration, Il Sheob Shin"

Competing interests. The authors have declared that no competing interests exist.

\section{Literature Cited}

1. Kitamura, Y.; Kato, Y.; Yasui, T.; Aizawa, H.; Ueno, S. Relation between increases in stomatal conductance of decorative sepals and the quality of antique-stage cut hydrangea flowers. Hort. J. 2017, 86(1), 87-93.

2. Thomas, D.; Gollnow, B. What cut flower is that? The essential care and handling guide for cut flower professionals. Kingston, Australia Government, RIRDC 2014, pp. 197.

3. da Costa, LC.; Finger, F.L. Flower opening and vase life of gladiolus cultivars: the sensitivity to ethylene and the carbohydrate content. Ornam. Hortic. 2016, 22(2), 147-153.

4. Kitamura, Y.; Ueno, S. Inhibition of transpiration from the inflorescence extends the vase life of cut hydrangea flowers. Hort. J. 2016, MI-016.

5. Alaey, M.; Babalar, M.; Naderi, R.; Kafi, M. Effect of pre-and postharvest salicylic acid treatment on physio-chemical attributes in relation to vase-life of rose cut flowers. Postharvest Biol. Technol. 2011, 61(1), 91-94.

6. Abreu, M.E.; Munné-Bosch, S. Salicylic acid may be involved in the regulation of droughtinduced leaf senescence in perennials: a case study in field-grown Salvia officinalis L. plants. Environ. Exp. Bot. 2008, 64(2), 105-112.

7. BAHRAN KINFE, L.G.; YOSIEF, R.; MEHARI, S.; MAEKELE, S.; RAO, G.S. Impact of different preservative solutions on extending vase life of rose (Rosa hybrid) cut flowers. Bioscience 2018, 3562.

8. Lü, P.; Cao, J.; He, S.; Liu, J.; Li, H.; Cheng, G.; Joyce, D.C. Nano-silver pulse treatments improve water relations of cut rose cv. Movie Star flowers. Postharvest Biol. Technol. 2010, 57(3), 196-202.

9. Mashhadian, N.V.; Tehranifar, A.; Bayat, H.; Selahvarzi, Y. Salicylic and citric acid treatments improve the vase life of cut chrysanthemum flowers. J. Agric. Sci. Technol. 2012, 14(4), 879-887. 
10. PUN, U.K.; ICHIMURA, K. Role of sugars in senescence and biosynthesis of ethylene in cut flowers. Jpn. Agric. Res. Q. 2003, 37(4), 219-224.

11. Van Ieperen, W.; Nijsse, J.; Keijzer, C.J.; Van Meeteren, U. Induction of air embolism in xylem conduits of pre-defined diameter. J. Exp. Bot. 2001, 52(358), 981-991.

12. Kazaz, S.; Doğan, E.; Kılıç, T.; Şahin, E.G.E.; Seyhan, S. Influence of holding solutions on vase life of cut hydrangea flowers (Hydrangea macrophylla Thunb.). Fresenius Environ. Bull. 2019, 28(4A), 3554-3559.

13. Asrar, A.W.A. Effects of some preservative solutions on vase life and keeping quality of snapdragon (Antirrhinum majus L.) cut flowers. J. Saudi Soc. Agric. Sci. 2012, 11(1), 29-35.

14. Edrisi, B.; Sadrpoor, A.; Saffari, V.R. Effects of chemicals on vase life of cut carnation (Dianthus caryophyllus L. 'Delphi') and microorganisms population in solution. J. Ornam. Hortic. 2015, 2:1-11.

15. Seyf, M.; Khalighi, A.; Mostofi, Y.; Naderi, R. Study on the effect of aluminum sulfate treatment on postharvest life of the cut rose 'Boeing' (Rosa hybrida cv. Boeing). J. Hortic. Sci. Biotechnol. 2012, 16:128-132.

16. Aros, D.; Silva, C.; Char, C.; Prat, L.; Escalona, V. Role of flower preservative solutions during postharvest of Hydrangea macrophylla cv. Bela. Cienc. Investig. Agrar. 2016, 43, $418-428$.

17. Kitamura, Y.; Ueno, S.; Aizawa, H.; Teoh, W. Differences in vase lives of cut hydrangea flowers harvested at different developmental stages. Hort. J. 2018, 87(2), 274-280.

18. Kazaz, S.; Kılıç, T.; Doğan, E.; Sekmen, Ş. Vase life extension of cut hydrangea (Hydrangea macrophylla) flowers. J. Hortic. Sci. Biotechnol. 2020, 95(3), 325-330.

19. Vahdati Mashhadian, N.; Tehranifar, A.; Bayat, H.; Selahvarzi, Y. Salicylic and citric acid treatments improve the vase life of cut chrysanthemum flowers. J. Agric. Sci. Technol. 2012, 14(4), 879-887.

20. Rafi, Z.N.; Ramezanian, A. Vase life of cut rose cultivars 'Avalanche' and 'Fiesta' as affected by Nano-Silver and S-carvone treatments. S. Afr. J. Bot. 2013, 86, 68-72.

21. Reid, M.S. Handling of cut flowers for export. Proflora bulletin 2009, 1-26.

22. Amin, O.A. II-Effect of some chemical treatments on keeping quality and vase life of cut chrysanthemum flowers. Middle East J. Agric. Res. 2017, 6(1), 221-243.

23. Ichimura, K.; Shimizu-Yumoto, H. Extension of the vase life of cut roses by treatment with 
sucrose before and during simulated transport. Bull. Natl. Inst. Flor. Sci. 2007, 7(7), 17-27.

24. Elgimabi, M.E.N.E. Vase life extension of Rose cut flowers (Rosa Hybrida) as influenced by silver nitrate and sucrose pulsing. Am. J. Agric. Biol. Sci. 2011, 6(1), 128-133.

25. Yagi, M.I.; Eldeen, M.; Elgemaby, N.E. Effect of bactericides and sucrose pulsing on longevity and vase life of rose cut flowers. Int. J. Sci. Basic Appl. Res. 2014, 14, 117-129.

26. Norikoshi, R.; Shibata, T.; Niki, T.; Ichimura, K. Sucrose treatment enlarges petal cell size and increases vacuolar sugar concentrations in cut rose flowers. Postharvest Biol. Technol. 2016, 116, 59-65. 


\section{Table}

Table 1. Vase life and main factor of senescence of hydrangea 'Verena' cut flowers kept in each holding solution treatment in 2019 and 2020.

\begin{tabular}{|c|c|c|c|c|c|c|c|}
\hline \multirow{2}{*}{ Year } & \multirow{2}{*}{$\begin{array}{l}\text { Pretreatment } \\
\text { solution }\end{array}$} & \multirow{2}{*}{$\begin{array}{c}\text { Transport } \\
\text { solution }\end{array}$} & \multirow{2}{*}{$\begin{array}{l}\text { Holding } \\
\text { Solution }^{z}\end{array}$} & \multicolumn{4}{|c|}{ Vase life (days) } \\
\hline & & & & Average $y$ & Min. ${ }^{x}$ & Max. & $\mathrm{MF}^{\mathrm{r}}$ \\
\hline \multirow{3}{*}{2019} & TW & TW & TW & $17.3 \mathrm{~b}$ & 17 & 18 & B \\
\hline & TW & TW & СРIII & $20.7 \mathrm{a}$ & 18 & 23 & $\mathrm{~B} / \mathrm{W}$ \\
\hline & TW & TW & SHQC & $18.0 \mathrm{ab}$ & 17 & 19 & $\mathrm{~W}$ \\
\hline \multirow{3}{*}{2020} & TW & TW & TW & $20.9 \mathrm{~b}$ & 20 & 21 & B \\
\hline & TW & TW & СРШII & $24.0 \mathrm{a}$ & 21 & 28 & $\mathrm{~B} / \mathrm{W}$ \\
\hline & TW & TW & SHQC & $22.3 \mathrm{~b}$ & 20 & 24 & $\mathrm{~W} / \mathrm{B}$ \\
\hline \multicolumn{8}{|c|}{$\begin{array}{l}\text { zW, tap water; CPII, } 1 \% \text { chrysal } \\
\text { hydroxquinoline }+100 \mathrm{mg} / \mathrm{L} \text { citric acid }\end{array}$} \\
\hline \multicolumn{8}{|c|}{$\begin{array}{l}\text { y Means in the same column with superscript with different letters (a and } b \text { ) are significantly } \\
\text { different at } p<0.05 \text {. }\end{array}$} \\
\hline
\end{tabular}


Table 2. Vase life and main factor of senescence of hydrangea 'Verena' cut flowers kept in each holding solution by treatments with combinations of postharvest solutions in 2020 .

\begin{tabular}{ccccccc}
\hline \multirow{2}{*}{$\begin{array}{c}\text { Pretreatment } \\
\text { Solution }\end{array}$} & Transport & Holding & \multicolumn{4}{c}{ Vase life (days) } \\
\cline { 4 - 7 } & solution & solution & Average $^{\mathrm{z}}$ & Min. & Max. & MF $^{\mathrm{x}}$ \\
\hline TW & TW & CPIII & $24.0 \mathrm{~b}$ & 21 & 28 & $\mathrm{~W}$ \\
TW & CPII & CPIII & $25.0 \mathrm{~b}$ & 20 & 29 & B \\
RVB & CPII & CPIII & $29.9 \mathrm{a}$ & 27 & 35 & B \\
FQ & FC & FC & $28.6 \mathrm{a}$ & 23 & 31 & B \\
\hline
\end{tabular}

$\bar{z}$ Means in the same column with superscript with different letters (a and b) are significantly different at $\mathrm{p}<0.05$.

y Minimum vase life and maximum vase life (day).

${ }^{x}$ Main factor in determining the vase life cut flowers (W, wilting; $\mathrm{B}$, browning) 
Table 3. Total solution uptake of hydrangea 'Verena' cut flowers kept in each holding solution treatment in 2019 and 2020.

\begin{tabular}{ccccc}
\hline \multirow{2}{*}{ Year } & $\begin{array}{c}\text { Pretreatment } \\
\text { solution }\end{array}$ & $\begin{array}{c}\text { Transport } \\
\text { solution }\end{array}$ & $\begin{array}{c}\text { Holding } \\
\text { Solution }\end{array}$ & ${\text { Total solution uptake }(\mathrm{g} / \mathrm{stem})^{\mathrm{z}}}^{2}$ \\
\hline \multirow{2}{*}{2019} & TW & TW & TW & $138.00 \mathrm{~b}$ \\
& TW & TW & CPII & $199.08 \mathrm{a}$ \\
& TW & TW & SHQC & $163.54 \mathrm{ab}$ \\
\hline \multirow{2}{*}{2020} & TW & TW & TW & $105.12 \mathrm{~b}$ \\
& TW & TW & CPWI & $135.28 \mathrm{a}$ \\
& TW & TW & SHQC & $132.71 \mathrm{a}$
\end{tabular}

${ }^{z}$ Means in the same column with superscript with different letters (a and b) are significantly different at $\mathrm{p}<0.05$. 
Table 4. Total solution uptake of hydrangea 'Verena' cut flowers kept in each holding solution by treatments with combinations of postharvest solutions in 2020 .

\begin{tabular}{|c|c|c|c|}
\hline $\begin{array}{c}\text { Pretreatment } \\
\text { Solution }\end{array}$ & $\begin{array}{l}\text { Transport } \\
\text { solution }\end{array}$ & $\begin{array}{l}\text { Holding } \\
\text { solution }\end{array}$ & Total solution uptake $(\mathrm{g} / \mathrm{stem})^{\mathrm{z}}$ \\
\hline TW & TW & CPIII & 141.18 a \\
\hline TW & CPIII & CPIII & $143.78 \mathrm{a}$ \\
\hline RVB & СРIII & CPIII & $164.98 \mathrm{a}$ \\
\hline $\mathrm{FQ}$ & FC & $\mathrm{FC}$ & $158.48 \mathrm{a}$ \\
\hline
\end{tabular}

${ }^{z}$ Means in the same column with superscript with different letters (a and b) are significantly different at $\mathrm{p}<0.05$.

\section{Figure}

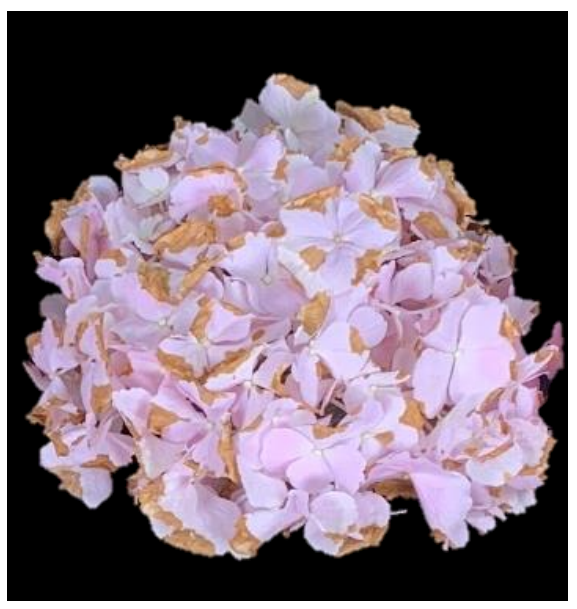

(a)

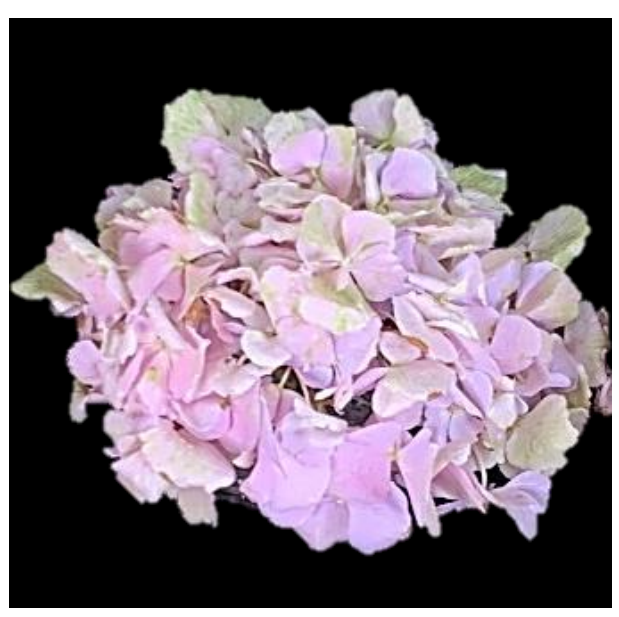

(b)

Fig. 1. The main senescence symptoms of hydrangea 'Verena' cut flowers (a, browning; b, wilting). 


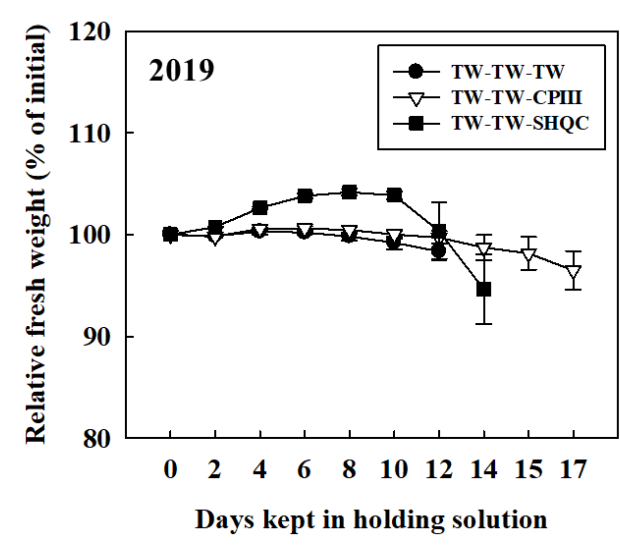

(a)

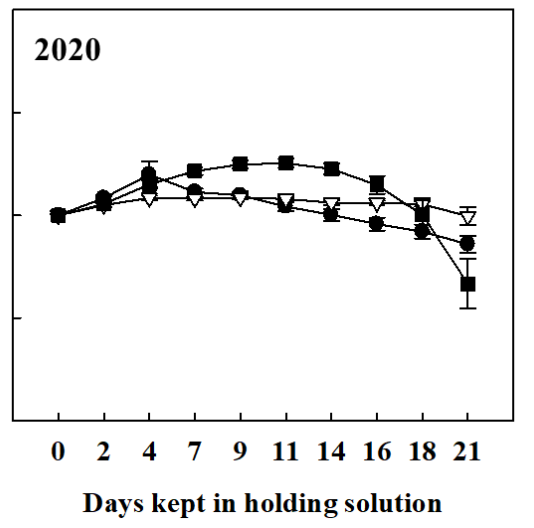

(b)

Fig. 2. Changes in the relative fresh weight of hydrangea 'Verena' cut flowers kept in each holding solution treatment in 2019 (a) and 2020 (b). Vertical bars indicate standard deviation of means $(n=9)$. 


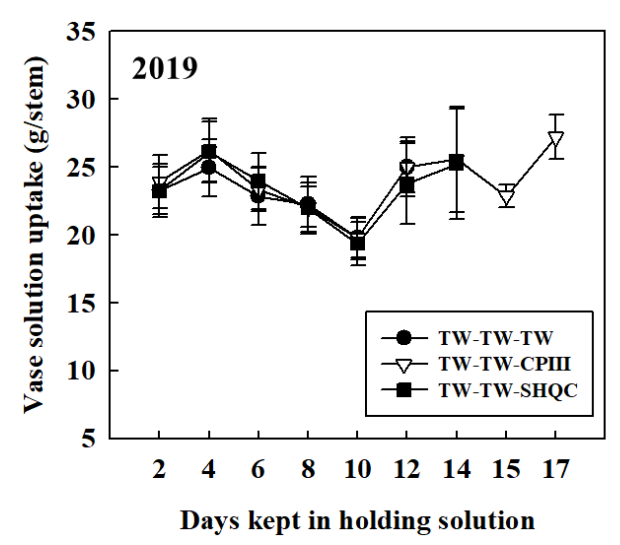

(a)

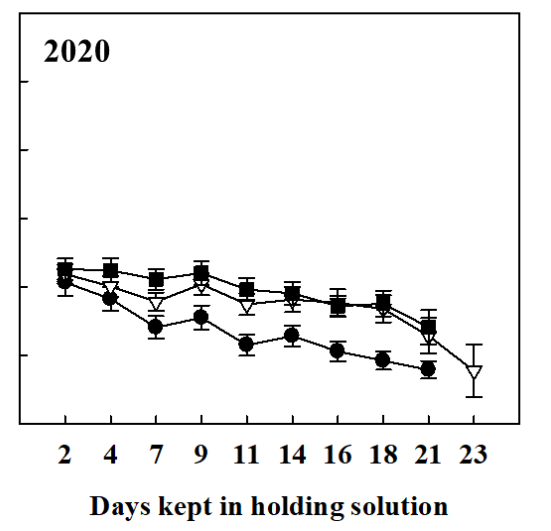

(b)

Fig. 3. Changes in the vase solution uptake of hydrangea 'Verena' cut flowers kept in each holding solution treatment in 2019 (a) and 2020 (b). Vertical bars indicate standard deviation of means $(n=9)$. 


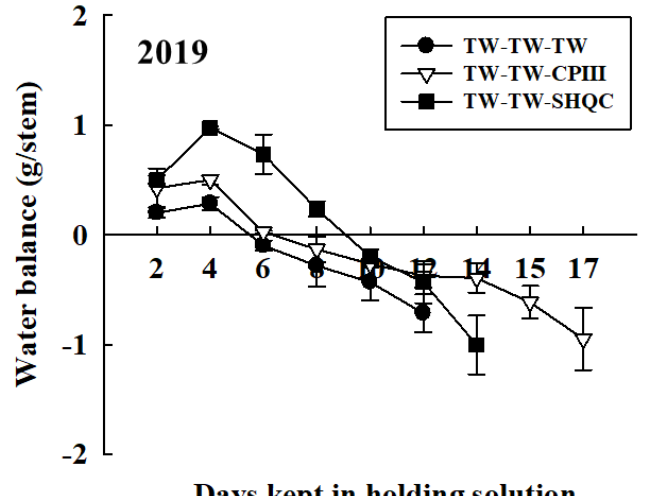

(a)

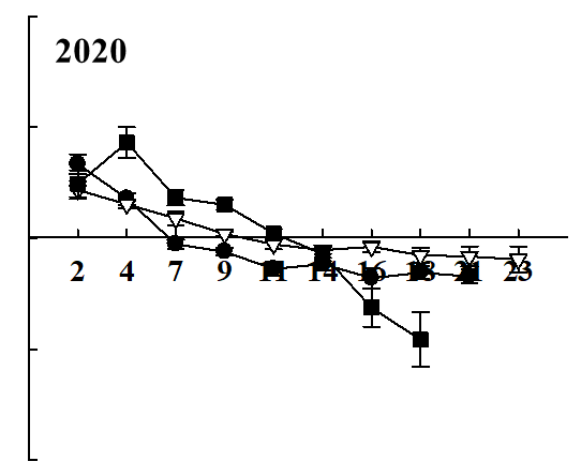

Days kept in holding solution

(b)

Fig. 4. Changes in the water balance of hydrangea 'Verena' cut flowers kept in each holding solution treatment in 2019 (a) and 2020 (b). Vertical bars indicate standard deviation of means $(n=9)$. 


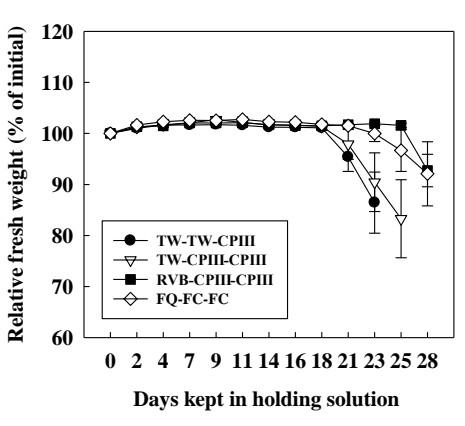

(a)

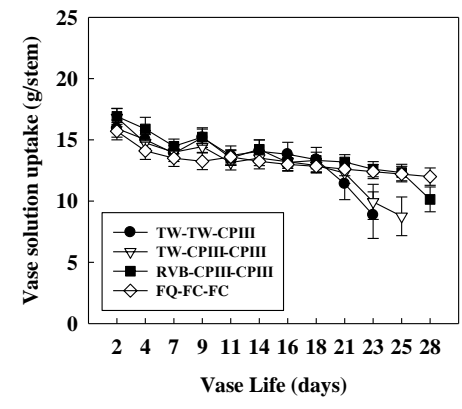

(b)

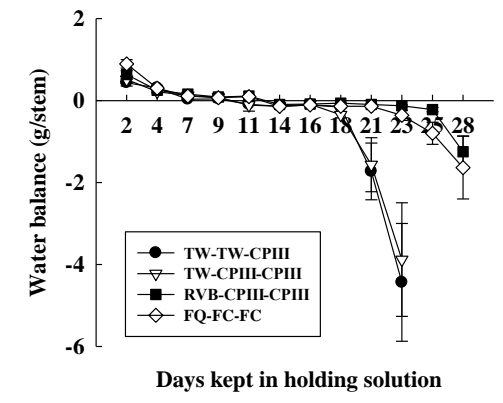

(c)

Fig. 5. Changes in the relative fresh weight (a), vase solution uptake (b), and water balance (c) of hydrangea 'Verena' cut flowers kept in each holding solution by treatments with combinations of postharvest solutions in 2020. Vertical bars indicate standard deviation of means $(n=9)$. 

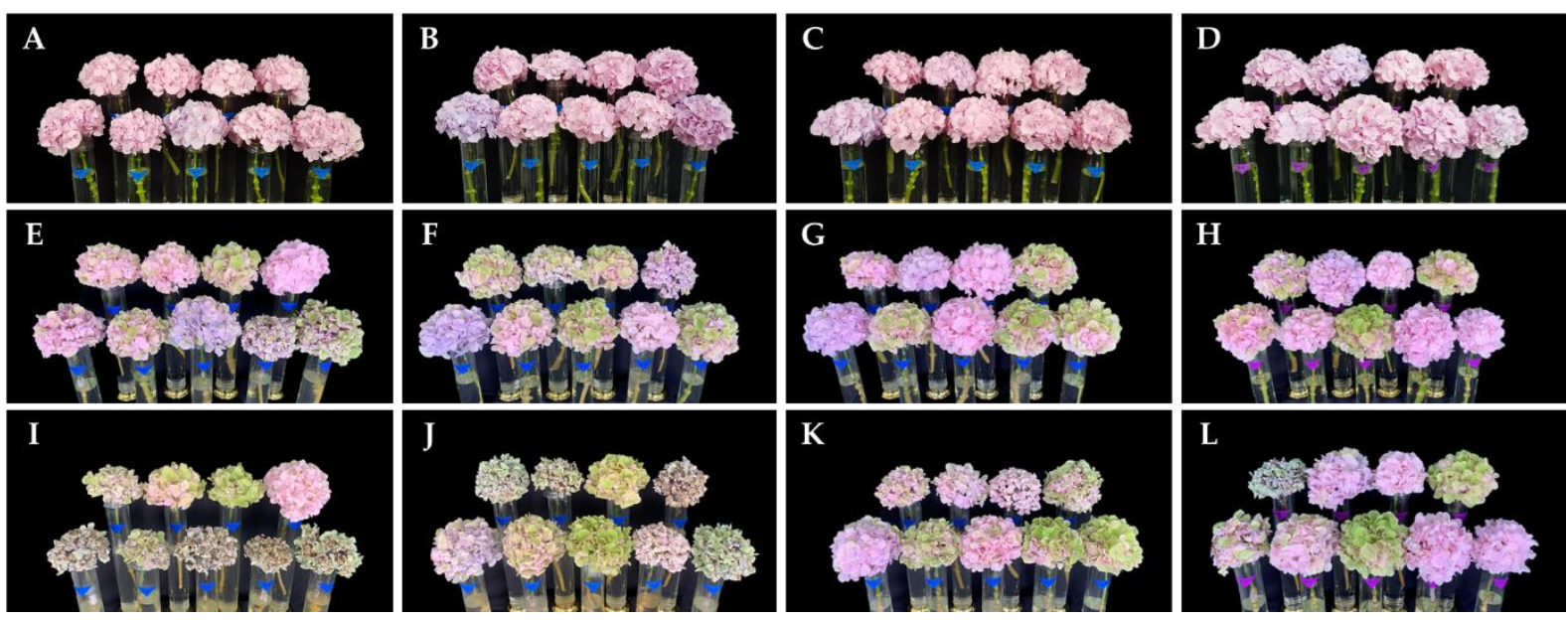

Fig. 6. Appearance of hydrangea 'Verena' cut flowers kept in each holding solution by treatments with combinations of postharvest solutions in 2020: 1st day after holding solution (A-D), 22th day after holding solution (E-H), 29th day after holding solution for treatment with combination of postharvest solutions of TWTW-CP II(A, E, I), TW-CPII-CPII (B, F, J), RVB-CPII-CPII (C, G, K), FQ-FC-FC $(\mathrm{D}, \mathrm{H}, \mathrm{L})$ 